\title{
THE PERFORMANCE OF A BORON-LOADED GEL-FUEL RAMJET
}

\section{A. Haddad, B. Natan, and R. Arieli}

\author{
Aerospace Engineering, Technion - \\ Israel Institute of Technology
}

Haifa 32000, Israel

The present work focuses on the possibility of combining the advantages of ramjet propulsion with the high energetic potential of boron. However, the use of boron poses two major challenges. The first, common to all solid additives to liquid fuels is particle sedimentation and poor dispersion. This problem is solved through the use of a gel fuel. The second obstacle, specific to boron-enriched fuels, is the difficulty in realizing the full energetic potential of boron. This could be overcome by means of an aft-combustion chamber, where fuel-rich combustion products are mixed with cold bypass air. Cooling causes the gaseous boron oxide to condense and, as a consequence, the heat of evaporation trapped in the gaseous oxide is released. The merits of such a combination are assessed through its ability to power an air-to-surface missile of relatively small size, capable of delivering a large payload to over a distance of about $1000 \mathrm{~km}$ in short time. The paper presents a preliminary design of a ramjet missile using a gel fuel loaded with boron. The thermochemical aspects of the two-stage combustion of the fuel are considered. A comparison with a solid rocket motor (SRM) missile launched under the same conditions as the ramjet missile is made. The boron-loaded gel-fuel ramjet is found superior for this mission.

\section{NOMENCLATURE}
AoA angle of attack
AP ammonium perchlorate
$C_{D} \quad$ drag coefficient
$C_{L} \quad$ lift coefficient
$C_{M} \quad$ pitching moment coefficient
$D \quad$ drag force

\footnotetext{
This is an Open Access article distributed under the terms of the Creative Commons Attribution-Noncommercial License 3.0, which permits unrestricted use, distribution, and reproduction in any noncommercial medium, provided the original work is properly cited.
} 


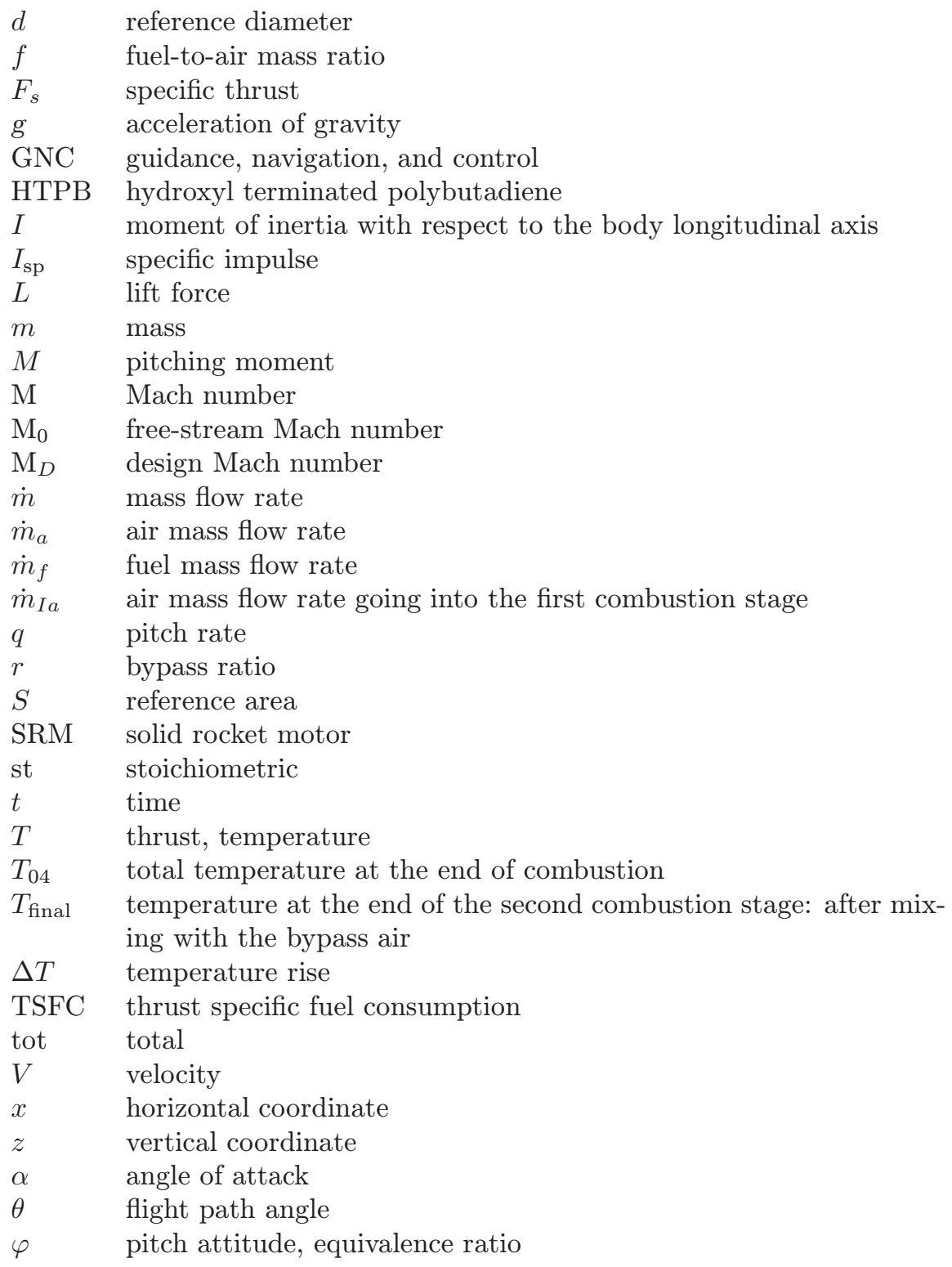

\section{INTRODUCTION}

The ramjet engine belongs to the air-breathing propulsion family and functions without any moving parts. The compression of intake air is achieved by the 
ram effect instead of a compressor. Air-breathing engines are more efficient than chemical rockets because they use the surrounding air as oxidizer. Eliminating moving parts allows operation at higher speeds and higher temperatures than turbojet engines; moreover, the system is much simpler.

Consequently, the ramjet engine is a very attractive propulsion system. However, relying on the ram effect for compression causes ramjet engines to have a significant shortcoming. At low flight speeds, the ramjet is very inefficient and unusable due to insufficient compression. The vehicle must, therefore, be accelerated to a supersonic speed before the ramjet engine kicks into action. A rocket booster is usually used for this purpose. Fry [1] presented an excellent review of the ramjet engine development and its applications. Operational systems powered by ramjets include Talos, Sea Dart, SA-6 Gainful, Kh-31, and Brahmos. The ramjet engine is also contemplated to power low-cost missile systems $[2,3]$. Most operational systems use liquid fueled ramjet engines; some are ducted rockets that use fuel-rich solid propellant in a gas-generator; none of the presently operational missiles is powered by solid fuel ramjets. The currently in development Meteor is based on boron-enriched solid-fuel ducted rocket.

Metals are commonly added to fuel to enhance performance. Among metal additives, boron is the most energetic. However, extracting the energy stored in boron is a rather complicated task [4]. Natan and Gany [5] proposed to complete the combustion and energy extraction of the boron particles in an aft-burner where bypass air is added.

Adding metal particles to a solid fuel is a common practice. Liquid fuel, on the other hand, presents a challenge when it comes to solid additives. The solid particles tend to sink in the liquid fuel when subjected to gravitational and centrifugal forces. This problem is solved if a gel fuel is used instead of a liquid fuel. Metal particles are evenly dispersed in a gel fuel and they do not have a tendency to sink. A gelled fuel has solid-like behavior until shear stress is applied. Under shear stress, the gel becomes less viscous and ends up behaving like a liquid. A gel fuel combines the storability properties of a solid fuel with the throttleability of a liquid fuel. An extensive review on gel fuels was conducted by Natan and Rahimi [6].

This work considers the possibility of combining the advantages of a liquid fuel ramjet and boron as fuel additive, through the use of a gelled fuel and a bypass system for better exploitation of boron energy. A feasibility study for such an arrangement is done through the design of a missile capable of delivering a 500-kilogram payload to a range of about $1000 \mathrm{~km}$. The missile is an air-tosurface missile, launched at Mach number 0.85, at an altitude of approximately $10 \mathrm{~km}$. The goal is to achieve the range and payload capability of a strategic missile, with a size and ease of launch comparable to those of a tactical missile. Two systems are considered for the aforementioned mission, one powered by an SRM and the other by a boron-loaded gel-fuel ramjet. 


\section{CALCULATING THE TRAJECTORY}

The performance parameter controlling this study is range. The range attainable is evaluated through a trajectory simulation. This simulation is based on a simple three-degree-of-freedom, pointmass model. The variables involved are the planar location, the angle of attack, and the flight path angle. Acting on the point mass are lift and drag forces, thrust, and

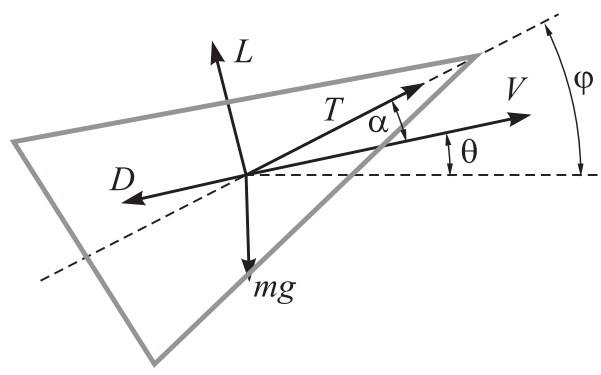

Figure 1 Model definition for trajectory simulation pitching moment:

$$
\left.\begin{array}{c}
\frac{d V}{d t}=-\frac{D}{m}-g \sin \theta+\frac{T \cos \alpha}{m} ; \\
\frac{d \theta}{d t}=-\frac{g}{V} \cos \theta+\frac{1}{m} \frac{L}{V}+\frac{1}{m} \frac{T \sin \alpha}{V} ; \\
\frac{d x}{d t}=V \cos \theta ; \quad \frac{d z}{d t}=V \sin \theta ; \quad \frac{d \varphi}{d t}=q ; \quad \frac{d q}{d t}=\frac{M}{I} ; \\
D=\frac{\rho S V^{2} C_{D}}{2} ; \quad L=\frac{\rho S V^{2} C_{L}}{2} ; \quad M=\frac{\rho S d V^{2} C_{M}}{2}
\end{array}\right\}
$$

The model, defined by Eqs. (1), is schematically presented in Fig. 1. The differential equations in question are solved with the 4th order Runge-Kutta method. The aerodynamic coefficients for various altitudes and Mach numbers were found using the Missile Datcom software [7]. The solver uses a bilinear interpolation on the Missile Datcom software output to find the aerodynamic coefficients at each time step. The solver takes into account the changes in the atmospheric properties with altitude.

\section{THE SOLID ROCKET MOTOR POWERED MISSILE}

This section deals with an air-launched missile, carrying a 500-kilogram payload. The missile size is limited by the carrying platform. The maximum possible range is found for a high-performance missile fitting into the geometrical constraints.

\subsection{Propulsion}

The factors leading the solid propellant choice are high performance and data availability. The propellant is composed of $70 \% \mathrm{AP}, 14 \% \mathrm{HTPB}$, and $16 \% \mathrm{Al}$, 
with a density of $1760 \mathrm{~kg} / \mathrm{m}^{3}$, a burning rate exponent of 0.21 , and a burning rate coefficient of $0.364 \mathrm{~cm} / \mathrm{s} / \mathrm{atm}^{0.21}$ [8]. The combustion temperature, calculated with the CEA [9] code, is $3200 \mathrm{~K}$. The theoretical characteristic velocity of such a propellant is $1626 \mathrm{~m} / \mathrm{s}$.

The grain geometry, a 10 convex-points star grain with a web fraction of 0.46 , was chosen to provide a satisfactory volume loading (80\%) and an almost neutral thrust profile. Reference [10] provides the methodology for the star grain burning calculations.

\subsection{Sizing of Rocket Motor Powered Missile}

This study deals with a missile launched from a plane. As a consequence, the size and weight of the missile are limited by the capabilities of the carrying platform. It is assumed that it is possible for the carrying aircraft to accommodate a missile of 600-millimeter diameter and 2500-kilogram weight. These values are chosen as the limits for the diameter and weight of the configuration.

As previously stated, the missile carries a 500-kilogram payload. The structure is assumed to constitute $10 \%$ of the total weight. The nozzle weight is assessed using [11]. The weights of other elements are evaluated based on missiles of similar size and weight, and are as follows: propellant $1665 \mathrm{~kg}$; structure $250 \mathrm{~kg}$; payload $500 \mathrm{~kg}$; GNC $70 \mathrm{~kg}$; nozzle $15 \mathrm{~kg}$; total mass $2500 \mathrm{~kg}$. The different component weights add-up to $825 \mathrm{~kg}$. The remaining $1665 \mathrm{~kg}$ are assumed to be all-propellant.

Following common design practice [12], the overall length-to-diameter ratio is set to 11 and the nose fineness ratio is set to 2 , as a compromise between low drag and good packing capabilities. The aft-body length to diameter ratio is set to 0.7. Assuming densities for the various components [12], the diameter and length accommodating all the missile units were found. The calculation takes into account the geometrical constraints on fineness ratios detailed above. The resulting design has a length of $6.54 \mathrm{~m}$ and diameter of $595 \mathrm{~mm}$.

The resulting geometry is integrated into the Missile Datcom software and a tail was provided to ensure static stability.

\subsection{Results}

The aerodynamic coefficients of the statically stable configuration found with the Missile Datcom software were used as input to the motion solver equations together with appropriate initial conditions. The nozzle throat area and launch conditions were determined iteratively to provide the longest possible range while maintaining static stability. The best range attainable with an SRM-powered, air-launched, 2500-kilogram missile similar to that described above, is about $105 \mathrm{~km}$, which is much less than the desired $1000 \mathrm{~km}$. The results of the simulation for the maximum range are shown in Fig. 2. It is worth remembering that 


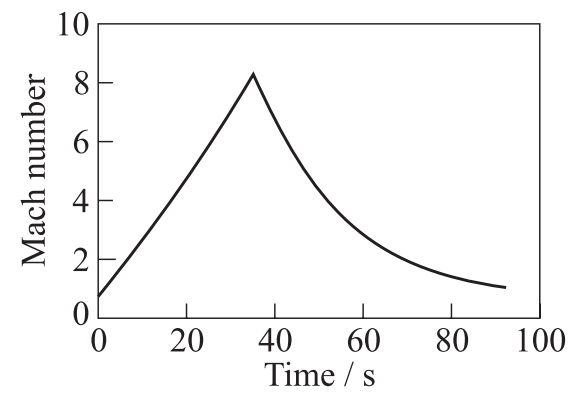

(a)

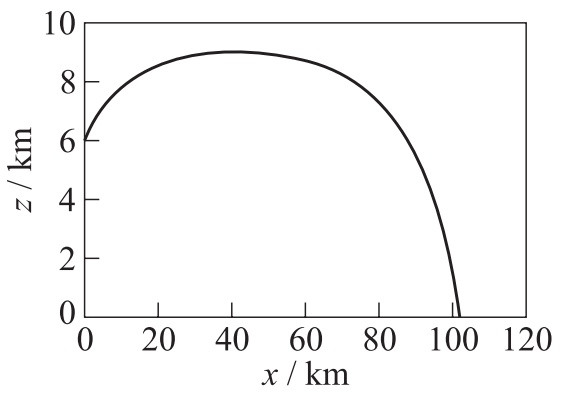

(b)

Figure 2 Mach number profile $(a)$ and trajectory $(b)$ of the SRM missile

operational ballistic missiles of ranges close to $1000 \mathrm{~km}$ have much larger dimensions and are almost 10 times heavier than the missile discussed in this section. Considering single-stage SRM-powered missiles in particular, some noteworthy examples are the Agni-I, the CSS-6, the SS-23 Spider, and the SS-26 Stone missiles.

\section{BORON AS FUEL ADDITIVE}

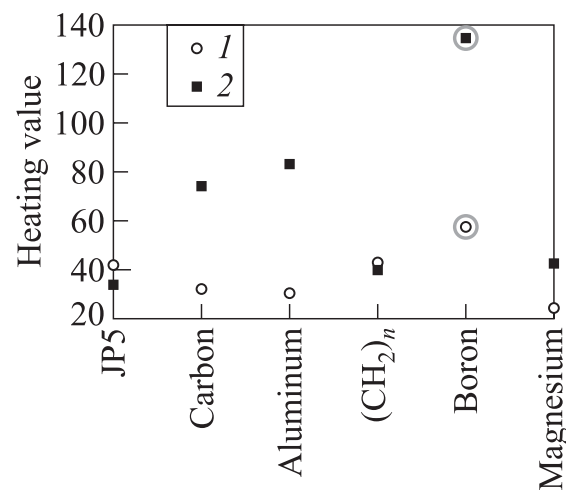

Figure 3 Heats of combustion of various fuels and additives [4]: gravimetric (1, in $\mathrm{MJ} / \mathrm{kg})$ and volumetric $\left(2\right.$, in $\left.\mathrm{kJ} / \mathrm{cm}^{3}\right)$ heating values

of the boron oxide formed during burning. A two-stage combustor can allow better utilization of boron energy. The air flow coming through the inlets is split at the diffuser exit. The first part is burned with boron-loaded gel fuel at 


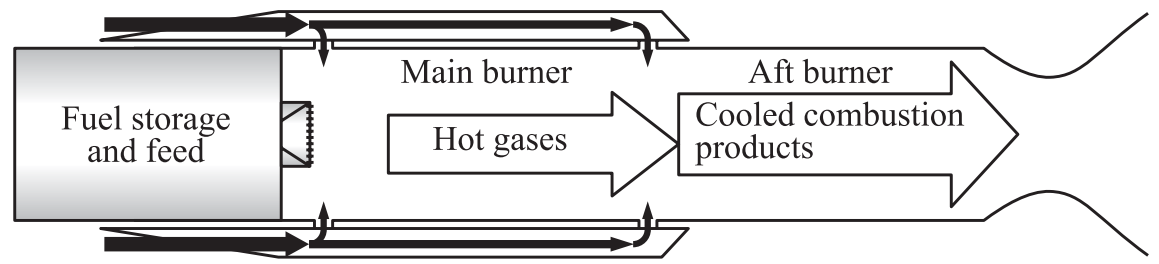

Figure 4 Flow path in the engine with two-stage combustion

a higher than stoichiometric fuel-to-air ratio. At the second stage, the bypass air is mixed with the combustion products. In illustration of this arrangement is shown in Fig. 4. With an adequately high bypass ratio, the addition of cold bypass air to the combustion products cools the mixture below the boron oxide boiling point, leading to the condensation of boron oxide and, consequently, to the release of the latent heat of vaporization stored in its gaseous form. For this setup to be advantageous, the overall fuel-to-air ratio should be less than the stoichiometric fuel-to-air ratio.

\subsection{Thermochemical Calculations}

The prediction of the combustion temperature and products was performed using the NASA Gordon and McBride code, CEA [9]. Two mixtures were examined. The first mixture served as a reference and consisted of a $100 \%$ Jet-A fuel mixed with an organic gellant. The second mixture was composed by $60 \%$ (wt.) Jet-A fuel mixed with the gellant and $40 \%$ (wt.) boron. Both fuel mixtures were assumed to have a temperature of $300 \mathrm{~K}$. The oxidant was air at $670 \mathrm{~K}$ and the reaction was assumed to take place at a pressure of $12 \mathrm{~atm}$. The program was used to find the equilibrium temperature and the equilibrium compositions, specifically the molar fractions of the boron compounds in the combustion products. The calculations were performed for various equivalence ratios. The results are depicted in Figs. 5 and 6. These calculations corresponded to the first combustion stage where a part of the compressed air was mixed with the fuel and ignited.

The choice of equivalence ratio for the first combustion stage was based on the quantity of boron oxide, relative to the other boron compounds. At an equivalence ratio $\varphi=2$, the molar fraction of boron oxide $\mathrm{B}_{2} \mathrm{O}_{3}$ was larger than the molar fractions of all but one of the remaining boron compounds (see Fig. 6). This equivalence ratio was chosen to be the working equivalence ratio for the first combustion step. At this equivalent ratio, the mixture without boron reached a temperature of $1830 \mathrm{~K}$, whereas the mixture loaded with boron reached $2220 \mathrm{~K}$.

The colder bypass air was then mixed with the hot combustion products leading, on the one hand, to the cooling of hot combustion gases and, on the 


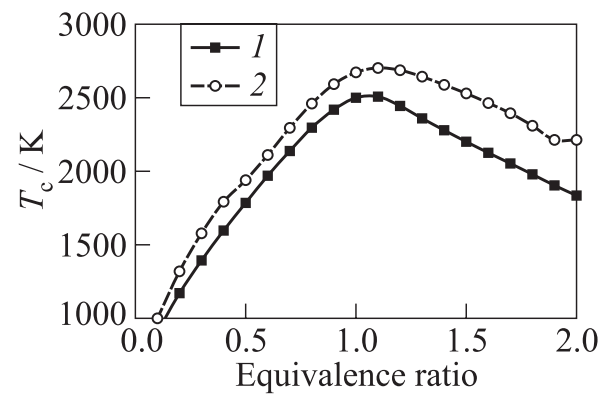

Figure 5 Combustion temperature for two gelled fuel mixtures as a function of equivalence ratio: 1 - Jet-A and gellant; and 2 - Jet- A, gellant, and boron

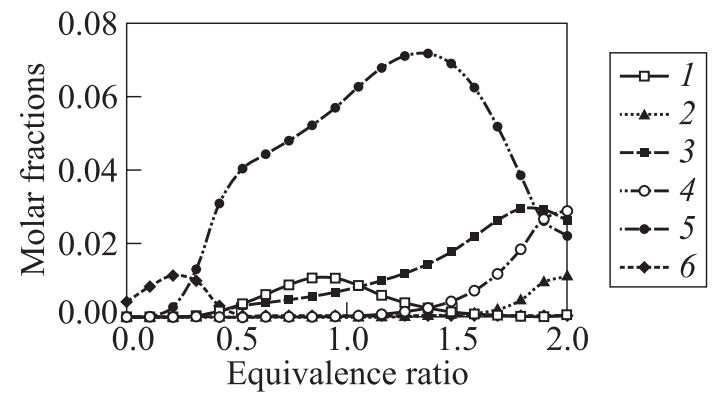

Figure 6 Dependence of molar fractions of boron compounds on the equivalence ratio: $1-\mathrm{BO}_{2} ; 2-\mathrm{B}_{2} \mathrm{O}_{2} ; 3-\mathrm{B}_{2} \mathrm{O}_{3} ; 4-\mathrm{HBO} ; 5-\mathrm{HBO}_{2}$; and $6-\mathrm{B}_{2} \mathrm{O}_{3}$ (liquid)

other hand, to the completion of combustion. It was assumed that after the addition of colder air, the gaseous $\mathrm{B}_{2} \mathrm{O}_{3}$, which was present at the end of the first combustion stage, did not react anymore with other species and was condensing only.

The temperature after mixing with the bypass air is shown in Fig. 7, as a function of the bypass ratio, defined as the ratio of the mass flow rate of bypass air to the mass flow rate of air at the first stage. The working-point bypass ratio was chosen such that the temperature of the gases exiting the combustor would be lower than the boiling point of boron oxide, but still high enough to allow for satisfactory acceleration of the exhaust gases. This bypass ratio has the value $r=3$ and leads to a final temperature of about $2060 \mathrm{~K}$.

The assumed Jet-A, gellant, and boron mixture has a stoichiometric fuelto-air ratio $f_{\text {st }}=0.08$. The equivalence ratio of the first combustion stage is 


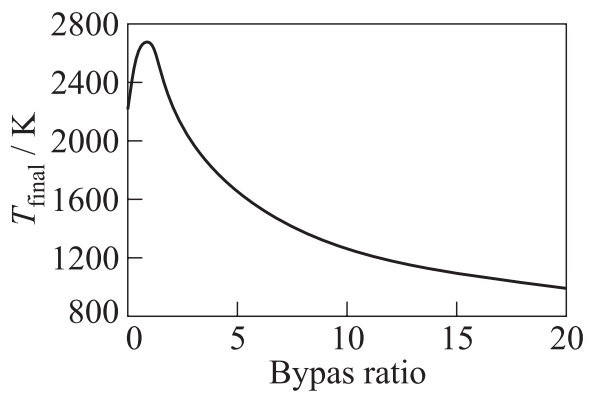

Figure 7 Temperature reached after adding bypass air to boron-fuel mixture combustion products as a function of bypass ratio

$\varphi=2.0$, leading to a first-stage fuel-to-air ratio of $f=0.16$. The overall fuel ratio:

$$
f_{\mathrm{tot}}=\frac{\dot{m}_{f}}{\dot{m}_{a \mathrm{tot}}}=\frac{\dot{m}_{f}}{\dot{m}_{a I}+r \dot{m}_{a I}}=\frac{f}{1+r},
$$

with a bypass ratio of 3 , is found to be $f_{\text {tot }}=0.04$, which gives an overall equivalence ratio of 0.5 . Burning Jet-A fuel only at this equivalence ratio would lead to a combustion product temperature of $1785 \mathrm{~K}$, i. e., about $200 \mathrm{~K}$ lower than the temperature reached with the two-stage combustor and the boronloaded gelled-fuel mixture. Moreover, burning the boron containing mixture at the above equivalence ratio in a single stage gives a temperature of $1950 \mathrm{~K}$, i. e., over $100 \mathrm{~K}$ lower than the double-stage combustion setup.

\subsection{Influence of Flight Mach Number and Altitude on Combustion Performance}

The temperature and pressure of the air supplied to the combustion chamber change with flight altitude and Mach number. Hence, the influence of Mach number and altitude was studied through the influence of pressure and temperature of the reacting air. Calculations at 12 atm and $670 \mathrm{~K}$ led to the determination of a working point for the equivalence ratio set to a value of two, and the bypass ratio set to a value of three.

First, the influence of pressure was established. The CEA calculations for the above values of equivalence ratio and bypass ratios, the air temperature set to $600 \mathrm{~K}$ and the pressure varying between 4 and $16 \mathrm{~atm}$, were performed. The resulting temperatures were almost equal, with a standard deviation of $0.21 \%$. This allowed considering the effect of pressure as negligible. The influence of air temperature was then determined. Since the pressure in the range considered had little effect, the calculations were performed only for a pressure of $8 \mathrm{~atm}$. 
The CEA calculations supplied the final temperature after adding the bypass air for various intake air temperatures. The results showed that the influence of temperature changes although small, was not negligible.

The relation between the supplied air temperature and the temperature rise attained could be linearly fitted with sufficient accuracy:

$$
\Delta T=1642-0.355 T
$$

The coefficient of determination of the fit had a value of 0.998 .

\subsection{Ideal Performance}

The above calculations refer to an ideal combustor with no losses in static pressure, 100 percent combustion efficiency, and total recovery of the latent heat of evaporation stored in the gaseous boron oxide formed at the first combustion stage. This ideal combustor was incorporated in an ideal ramjet assuming 100 percent efficiency, and exhaust gases pressure equal to ambient pressure. Operated at Mach number 3.5 at an altitude of $12 \mathrm{~km}$, with an overall fuel-toair ratio of 0.04 , the engine will provide $750 \mathrm{~N}$ of thrust, for each kilogram per second of air flow. The calculated trends of the specific impulse and the thrust specific fuel consumption (TSFC) with an overall fuel-to-air ratio $f_{\text {tot }}=0.04$ are shown in Fig. 8 for a gelled fuel with and without boron. Figure 8 demonstrates the superiority of a two stage burner setup with a boron-loaded fuel over more conventional burners and fuels.

Finally, the influence of the bypass ratio on the behavior of the specific impulse and the specific thrust, when the ideal ramjet is operated at Mach 3.5 at $12 \mathrm{~km}$, is shown in Fig. 9. The theoretical specific impulse shows impressively high values; however, this comes at the expense of specific thrust. Because of
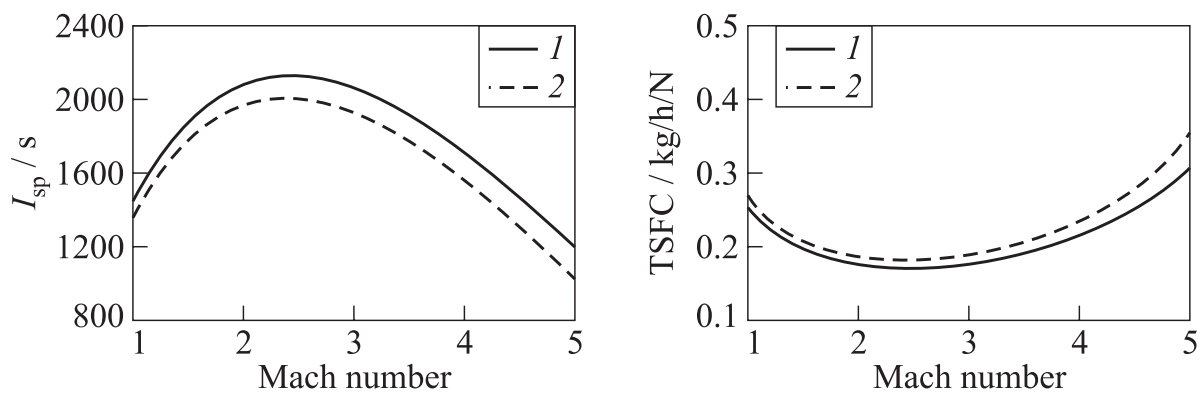

Figure 8 Ideal ramjet performance for two fuel mixtures $(1-$ Jet-A and boron; and 2 - Jet-A) with overall fuel-to-air ratio set to 0.04 


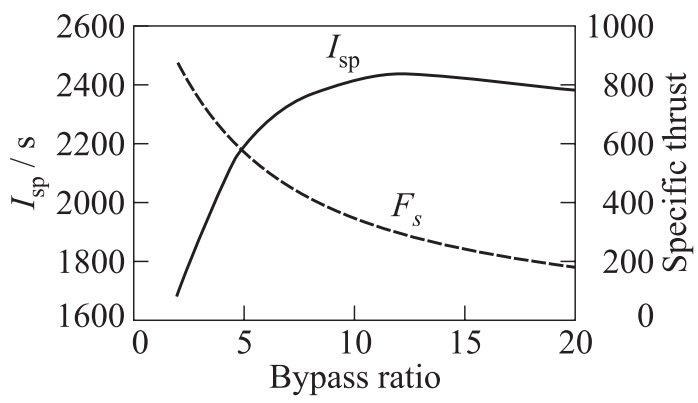

Figure 9 Ideal ramjet performance parameters at $12 \mathrm{~km}$ for various bypass ratios

this behavior, the choice of bypass ratio becomes a compromise between a high specific impulse and a satisfactory specific thrust.

\subsection{Variable Equivalence Ratio}

As stated above, the working equivalence ratio chosen for the first combustion step was $\varphi=2$. The effect of changing this equivalence ratio was studied through the variation of the ideal temperature calculated using CEA (Fig. 10). Based on the graph shown in Fig. 10, the variation of the final combustion temperature for a bypass ratio of 3 with the equivalence ratio of the first stage and, consequently, with the fuel-to-air ratio or the fuel mass flow rate was found. The result is shown in Fig 11.

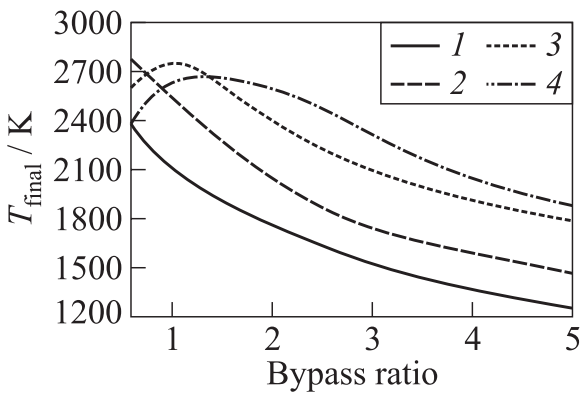

Figure 10 Final temperature after adding the bypass air vs. bypass ratio for various equivalence ratios at the first combustion stage: $1-\varphi=1.2 ; 2-1.6$; $3-2.4 ;$ and $4-\varphi=2.8$

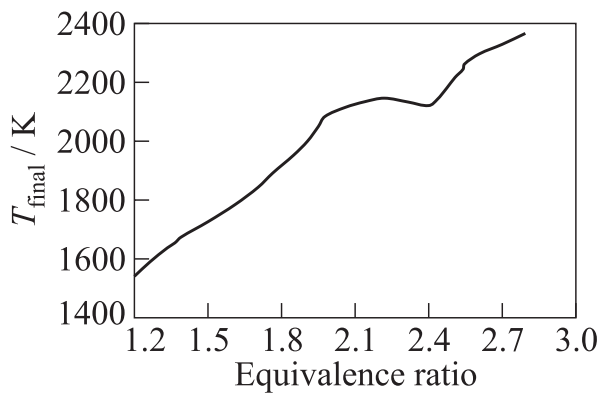

Figure 11 Final temperature variation as a function of equivalence ratio for a bypass ratio of 3 


\section{RAMJET MISSILE}

This section describes the intake design and the sizing of a basic missile, powered by the ramjet engine discussed in this work, suitable for the mission described in section 1.

\subsection{Air Intakes}

\subsubsection{Configuration}

Twin two-dimensional aft-mounted inlets were considered. Mounting inlets outside the main body increases the drag; however, a nose inlet reduces the volume available for the missile subsystems and the payload. Aft-mounted inlets usually offer less pressure recovery than forward inlets, but they weigh less than forward inlets and have little impact on the payload delivery [12]. For simplicity, an external compression mechanism was chosen. Moreover, external compression is less sensitive to internal fluctuations in the flow, as opposed to internal or mixed compression and is suitable for the selected Mach number regime.

\subsubsection{Supersonic diffuser}

The supersonic external compression diffuser slows the incoming flow through a series of oblique shocks followed by a terminal normal shock transforming the flow into subsonic regime. As the flow passes each shock wave, it loses stagnation pressure. As the shocks get stronger, the losses become higher. An important parameter of a supersonic diffuser is the total pressure recovery; thus, a series of small deflections, i. e., a series of weaker oblique shocks, is better than a more sudden large deflection.

The number of shocks leading to an optimal pressure recovery depends on the free-stream Mach number. As the Mach number grows, so do the number of shocks needed, the limiting case being an isentropic compression ramp. However, increasing the number of oblique shocks leads to complicating the geometry and to increasing the weight and length of the intakes. This, in turn, leads to an increased drag. If the Mach number is not high enough, the improvement achieved when using an isentropic compression ramp in terms of pressure recovery does not justify the losses and complications due to a longer ramp. Once the number of shocks and free-stream Mach number are determined, the total flow turning angle can be chosen to obtain optimal pressure recovery. Seddon and Goldsmith [15] supply the data necessary for determining the optimal shock number and the optimal total turning angle for various design Mach numbers.

When the intake is operating at the design Mach number, all the oblique shocks are focused on the lip and the terminal normal shock is in the throat 


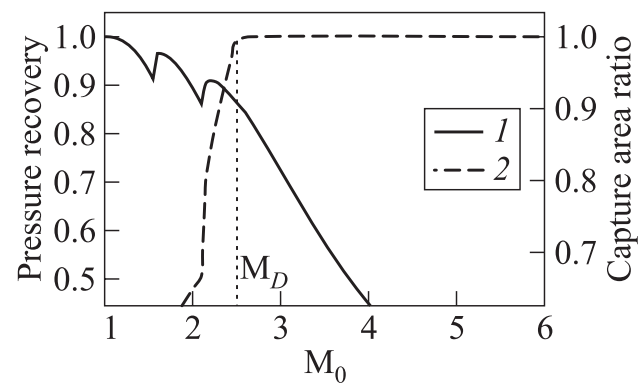

(a)

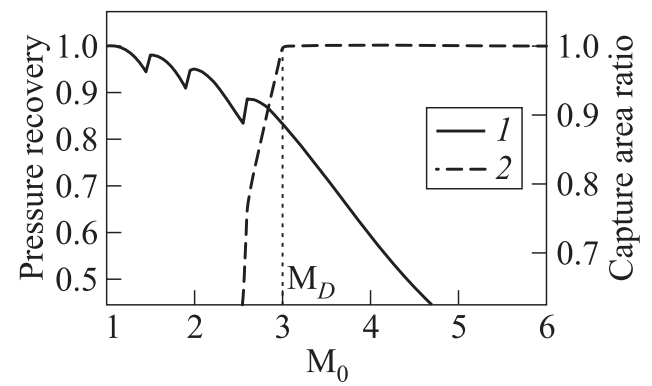

(b)

Figure 12 Off-design performance of an inlet designed for $\mathrm{M}=2.5(a)$ and $3.5(b)$ : 1 - total pressure recovery; and 2 - capture area ratio

section. Along with the flow deflection angles and the oblique wave angles, this allows the determination of the supersonic diffuser geometry. With the geometry and the wave structure at the design Mach number known, it is now possible to evaluate off-design performance of various supersonic diffusers designed earlier. The off-design pressure recovery and capture area ratio are calculated using the INLET software [16]. Sample design parameters are presented in Fig. 12. For each compression ramp design, there exists a Mach number below which oblique shocks are replaced with a detached normal shock followed by subsonic flow. This shows as instability in Figs. $12 a$ and $12 b$. Also noticeable for low Mach numbers is the drop in capture area which leads to lower thrust due to lower air mass flow rate and to additional drag due to spillage. This behavior could cause a problem if the takeover Mach number is much lower than the design Mach number and not enough thrust is produced to overcome drag and accelerate to cruise speed.

The performance of the engine was evaluated with various inlets and at various flight speeds and altitudes. Efficiencies for the various components were assumed and drag coefficient, including additive drag when spillage occurs, was evaluated for a preliminary geometry using the Missile Datcom software. The 


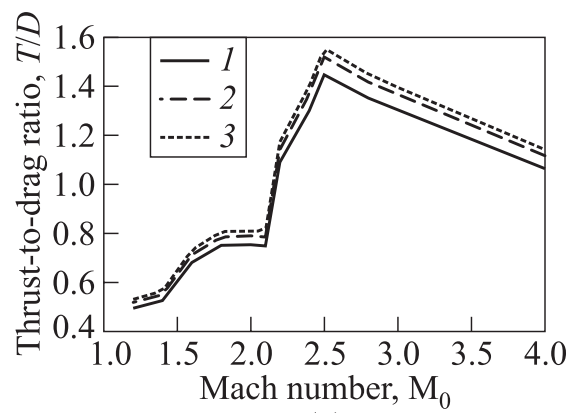

(a)

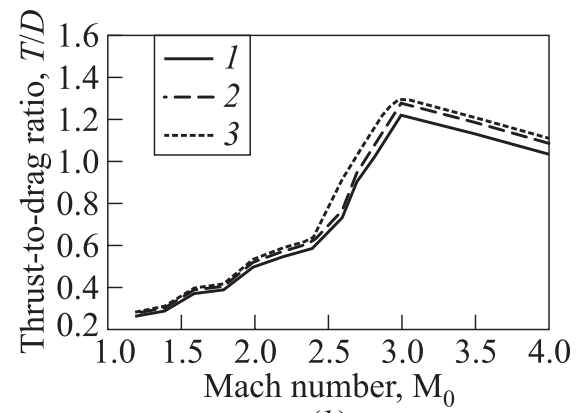

(b)

Figure 13 Performance of the inlet designed for Mach number $2.5(a)$ and $3.5(b)$ : $1-8 \mathrm{~km} ; 2-10$; and $3-12 \mathrm{~km}$

goal was to have a wide enough range of Mach numbers where thrust was higher than drag, and have the possibility to choose a ramjet-takeover Mach number where thrust was about $20 \%$ higher than drag in order to have sufficient acceleration. The reference area, i. e., the largest cross-sectional area, and the air intake areas were determined iteratively. Both these quantities were varied until the performance of some of the inlets was satisfactory. In the final round, the cross-sectional diameter was set to $420 \mathrm{~mm}$ and the intake inlet area was set to $0.025 \mathrm{~m}^{2}$. Sample results are presented in Fig. 13. The above calculations were performed in order to choose a suitable inlet and decide at which Mach number the ramjet engine will start operating. Based on the results, the inlet designed for optimal performance at a design Mach number of 2.5 was chosen, because it offered a good performance over the widest range of Mach numbers and altitude among the studied intakes. It was decided to accelerate the missile with a booster to a takeover Mach number of about 2.2. This Mach number allows the generation of at least $20 \%$ more thrust than drag.

The supersonic diffuser is followed by a throat section, then a subsonic diffuser which slows the flow down even more. The flow is finally slowed down one more time when dumped into the combustion chamber. The Mach number at that point ranges between 0.2 and 0.3 .

\subsection{Sizing of Ramjet Powered Configuration}

A basic configuration with a cross-sectional diameter of $420 \mathrm{~mm}$ and an intake inlet area of $0.025 \mathrm{~m}^{2}$ was assumed in order to inspect the engine performance. The intakes were identical and rectangular with a constant width of $0.25 \mathrm{~m}$ and a height starting at $0.1 \mathrm{~m}$ at the inlets and varying as the intake cross-sectional area varied. The width was chosen much larger than the height in order to reduce 
drag and increase the lifting behavior of the inlets. The length of the supersonic diffuser was $0.14 \mathrm{~m}$ and the subsonic diffuser including the throat section was $0.2 \mathrm{~m}$ long. The bypass duct led the bypass air from the subsonic diffuser to be mixed with the combustion products. The main combustion chamber should be long enough to ensure good combustion. The length chosen was $0.5 \mathrm{~m}$, which was actually the bypass duct length. The intakes were thus about $0.85 \mathrm{~m}$ long. Based on the above, the length of the aft-mixing chamber for the completion of the combustion was $0.8 \mathrm{~m}$.

The nozzle was designed to expand the hot gases to ambient pressure at an altitude of $8 \mathrm{~km}$. The exit Mach number was about 2.27 and the exit area was $0.138 \mathrm{~m}^{2}$, corresponding to a diameter of almost $420 \mathrm{~mm}$. Choosing the nozzle half angle to be small enough to avoid separation, the length of the ramjet nozzle was about $0.7 \mathrm{~m}$.

The nozzle and the intakes remained fixed during the subsequent iterations. The 500-kilogram payload and the 75-kilogram GNC system remained constant too. The fuel feed and atomization system was assumed to weigh $5 \mathrm{~kg}$. The fixed-geometry ramjet nozzle was assumed to weigh $15 \mathrm{~kg}$ and the jettisonable solid rocket booster nozzle was supposed to weigh $5 \mathrm{~kg}$. The structure weight should change with the geometry. However, it was assumed to be fixed at $240 \mathrm{~kg}$, including the inlets, as a conservative step.

The sizing procedure was similar to that of the SRM-powered missile. The length occupied by each component was evaluated. The iterative process started by limiting the missile length to $8 \mathrm{~m}$, because of carrying capability and bending stability. Design iterations showed that it was possible to opt for the integrated booster option. The combustion chamber was thus filled with booster propellant. The booster grain had the same shape and composition as the grain used for the SRM powered missile. The remaining space was filled with boronloaded gelled fuel, and iterations were made to find a quantity sufficient to reach the required range. The mass and length component break-up of the final configuration is detailed in Table 1. Figure 14 shows a representation of the various lengths. Finally, it should be noted that extra fuel has been provided for terminal maneuvers and that the Missile Datcom software results indicate that the body and inlets can produce enough lift to carry the missile weight during cruising without having to install Table 1 Ramjet missile final configuration

\begin{tabular}{lcc}
\hline Component & Mass, kg & Length, m \\
\hline GNC & 70 & 0.85 \\
Payload & 500 & 2.1 \\
Propellant & 247 & 1.3 \\
Gel fuel & 405 & 2.7 \\
Other & 10 & 0.2 \\
Nozzles & $15+5$ & 0.7 \\
Structure & 240 & \\
\hline Total & 1487 & 7.85 \\
\hline End of Boost & 1240 & \\
Empty & 840 & \\
\hline
\end{tabular}
wings. 


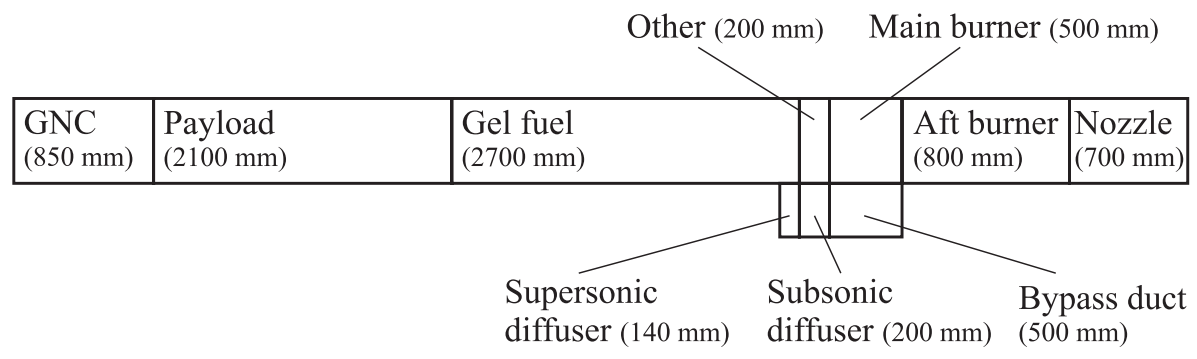

Figure 14 Representation of lengths of ramjet missile subsections

\subsection{Results}

The missile above was considered in three different modes of ramjet operation: constant fuel-to-air ratio, constant fuel mass flow rate, and variable fuel mass flow rate and fuel-to-air ratio. The bypass ratio was assumed to be constant and equal to three. The aerodynamic coefficients calculated for the missile showed that the body and the inlets produced enough lift to carry the body during the sustain phase. During the ramjet operation, the flight was assumed to be leveled and the angle of attack was changed to ensure that lift produced could counter the missile weight. During the boost and unpowered phases, the angle of attack (AoA) was set to zero in order to reduce drag. The ramjet operation started at a Mach number of 2.4 after the end of the booster operation. The calculations were made assuming a combustion efficiency of 0.98 , a subsonic diffuser pressure recovery of 0.9 , a combustor pressure recovery of 0.97 , and a nozzle pressure recovery of 0.98. Earth curvature was not taken into account while finding the range; hence, the actual range will be longer than the calculated range.

\subsubsection{Constant fuel-to-air ratio}

In this case, the fuel-to-air ratio during ramjet operation was kept constant at $f=0.04$. The air mass flow rate varies with the flight conditions and the fuel mass ratio varies accordingly. Using this setup, the missile reached a range of $1030 \mathrm{~km}$ within $17 \mathrm{~min}$ from launch. The ramjet operated for $15 \mathrm{~min}$. The variation of lift and weight during ramjet operation, along with the angle of attack can be seen in Fig. 15. This figure shows that the angle of attack during the sustain phase ensures that the lift and weight are almost equal. During ramjet operation, the average TSFC was $0.18 \mathrm{~kg} / \mathrm{h} / \mathrm{N}$ and the average specific impulse was $2190 \mathrm{~s}$. Their variation with time is shown in Fig. 16. The trajectory is shown in Fig. 17 and the variations of Mach number, thrust, and drag are presented in Fig. 18. 


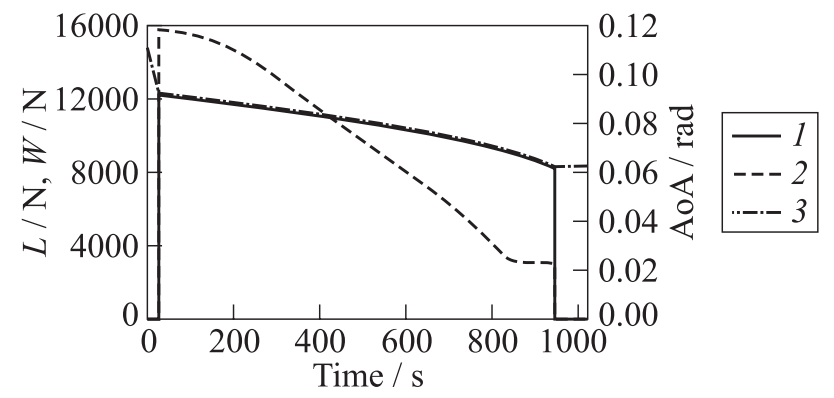

Figure 15 Angle of attack (1), lift (2), and weight (3) variations with time for the constant air-to-fuel ratio case

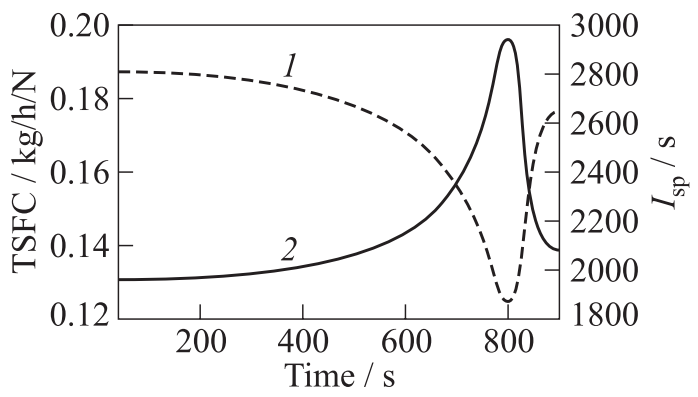

Figure 16 Thrust specific fuel consumption (1) and specific impulse (2) during the sustain phase for the constant air-to-fuel ratio case

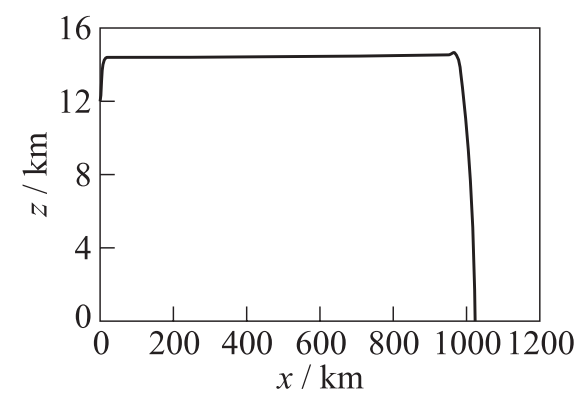

Figure 17 Trajectory of the ramjetpowered missile with constant fuel-to-air ratio

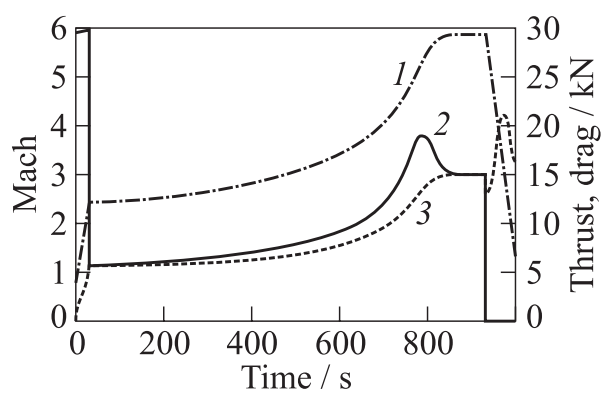

Figure 18 Mach number (1) and thrust (2) profiles for the ramjet powered missile with constant fuel-to-air ratio; $3-$ drag 


\subsubsection{Constant fuel mass flow rate}

This was the simplest operation mode: the fuel mass ratio was kept constant during the whole ramjet operation. The variation of air mass flow rate with flight conditions will lead to changes in the fuel-to-air ratio. This will affect the temperature of the combustion products. Four different fuel mass flow rates, ranging from 0.3 to 0.5 , were studied and the results are presented below in Fig. 19. These mass flow rates ensure enough thrust to accelerate the vehicle to sufficiently high Mach numbers. For all the fuel mass flow rates considered, the range requirement is met. Lowering the fuel mass flow rate will lead to a more efficient trajectory and fuel can be saved at the expense of the impact speed, as can be seen by comparing the results for $\dot{m}_{f}=0.4$ and $0.3 \mathrm{~kg} / \mathrm{s}$.

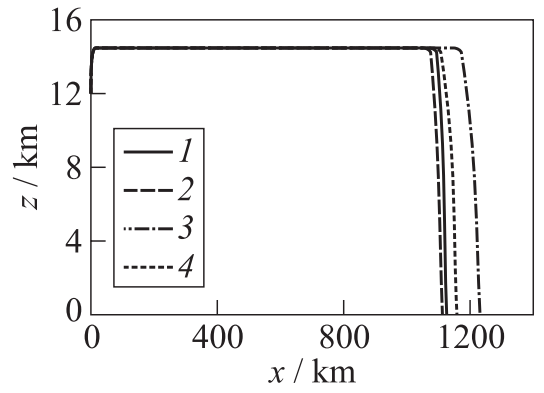

(a)

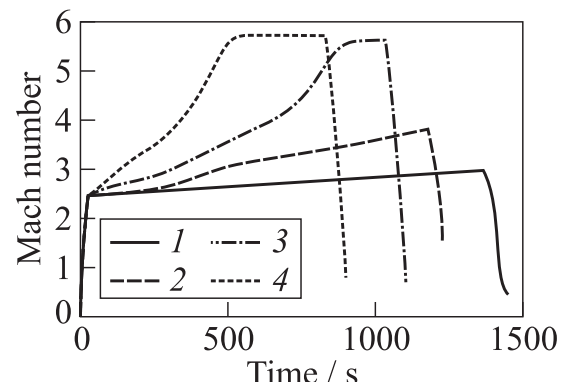

(b)

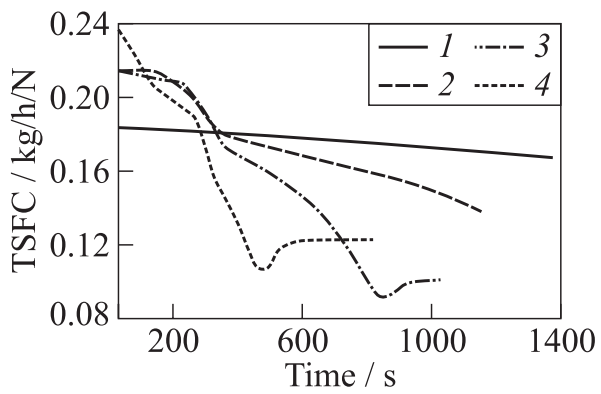

(c)

Figure 19 Trajectory (a), Mach number profile (b), and TSFC variation $(c)$ of the ramjet powered missile with constant fuel mass flow: $1-0.3 \mathrm{~kg} / \mathrm{s} ; 2-0.35 ; 3-0.4$; and $4-0.5 \mathrm{~kg} / \mathrm{s}$

\subsubsection{Variable fuel mass flow rate and fuel-to-air ratio}

In this case, the fuel mass flow rate was changed in order to accelerate to a certain cruise Mach number, and maintain it. In order to achieve this, at each 


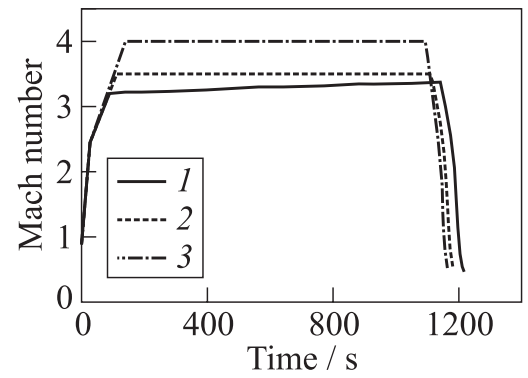

Figure 20 Mach number change with time for the ramjet missile with various sustain Mach numbers: $1-3.2 ; 2-$ 3.5 ; and $3-4.0$

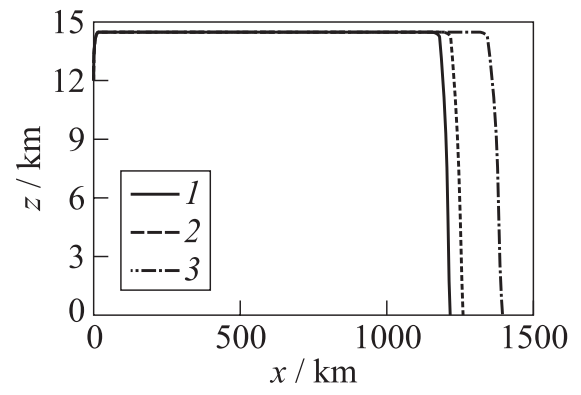

Figure 21 Trajectories for the ramjet missile with variable fuel mass flow rate and fuel-to-air ratio: 1 - sustain Mach number $=3.2 ; 2-3.5$; and $3-$ sustain Mach number $=4.0$

integration time step, the solver compared the thrust to the drag and increased, decreased, or leaved unchanged the fuel mass flow rate. The behavior of the Mach number can be seen in Fig. 20 .

The trajectories are shown in Fig. 21. This figure shows clearly the effect of the sustain Mach number on the attainable range. The average TSFC and the average specific impulse in the sustain phase are detailed in Table 2. The trajectories in Fig. 21 and the values in Table 2 show that a Mach number of 4 in the sustain phase offers a very good performance since in less than $18 \mathrm{~min}$, more than $1300 \mathrm{~km}$ can be travelled, with an impact Mach number of about 0.5 .

\section{CONCLUDING REMARKS}

The present work proves the feasibility of a concept that combines the merits of ramjets, gelled fuels, and boron additives through the design of an air-launched missile of a relatively small size. The designed missile has a total weight under $1500 \mathrm{~kg}$, and delivers the 500-kilogram payload to a distance of more than $1000 \mathrm{~km}$ in about $17 \mathrm{~min}$. Such a missile is a great improvement over rocket powered missiles of similar size, which have much shorter ranges. The SRM-powered missile studied in this paper had a range of less than $250 \mathrm{~km}$, for a total weight of $2500 \mathrm{~kg}$. Missiles for ranges close to $1000 \mathrm{~km}$ are of a much greater size and are difficult and slow to deploy. It was shown that the fuel quantity used can be 
reduced through appropriate fuel flow control or, alternatively, farther targets can be reached with the same amount of fuel. This paper shows the advantage of adding bypass air to the boron-enriched fuel combustion products and the simulation led to an impressive average theoretical specific impulse of $2190 \mathrm{~s}$. This system can further be improved by optimizing the booster propellant quantity, reducing the fuel consumption through better control, slightly reducing the flight velocity, designing more efficient intakes, and burning better fuel mixtures.

\section{REFERENCES}

1. Fry, R. S. 2004. A century of ramjet propulsion technology evolution. J. Propul. Power 20(1):27-58.

2. Nabity, J., P. Hudson, and J. Loundagin. 1999. Developmental testing of the fasthawk combustor. AIAA Paper No. 1999-431.

3. Minard, J.-P., M. Hallais, and F. Falempin. 2002. Low cost ramjet technology for tactical missile application. AIAA Paper No. 2002-3765.

4. Gany, A. 2006. Comprehensive consideration of boron combustion in air breathing combustion. AIAA Paper No. 2006-4567.

5. Natan, B., and A. Gany. 1993. Combustion characteristic of a boron-fueled solid fuel ramjet with aft-burner. J. Propul. Power 9(5):694-701.

6. Natan, B., and S. Rahimi. 2002. Status of gel propellants in year 2000. In: Combustion of energetic materials. Eds. K. K. Kuo and L. DeLuca. New York: Begell House. 172-94.

7. Blake, W.B. 1998. Missile datcom user's manual - 1997 Fortran 90 revision. AFRL-VA-WP-TR-1998-3009. Air Vehicles Directorate, Air Force Research Laboratory, Air Force Materiel Command, Wright Patterson Air Force Base, OH.

8. Sutton, G. P., and O. Biblarz. 2001. Rocket propulsion elements. 7th ed. New York: Wiley-Interscience. Ch. 11.

9. McBride, B. J., and S. Gordon. 1996. Computer program for calculation of complex chemical equilibrium compositions and applications. NASA RP 1311. Lewis Research Center, Cleveland, USA.

10. Ricciardi A. 1992. Generalized geometric analysis of right circular cylindrical star perforated and tapered grains. J. Propul. Power 8(1):51-58.

11. Humble, R.W., G. N. Henry, and W. J. Larson. 1995. Space propulsion analysis and design. 1st ed. New York: The McGraw-Hill Companies, Inc.

12. Fleeman, E. L. 2001. Tactical missile design. AIAA education ser. Reston, VA: AIAA. Chs. 2-4.

13. Gany, A. 1993. Combustion of boron-containing fuels in solid fuel ramjets. In: Combustion of boron-based solid propellants and solid fuels. Eds. K. K. Kuo and L. Deluca. New York, Boca Raton: CRC and Begell House. 91-112.

14. Yeh, C. L., and K. K. Kuo. 1996. Ignition and combustion of boron particles. Prog. Energy Combust. Sci. 22:511-41.

15. Seddon, J., and E. L. Goldsmith. 1999. Intake aerodynamics. 2nd ed. London: Blackwell Science. Ch. 5.

16. Mattingly, J. D, W. H. Heiser, and D. T. Pratt. 2002. Aircraft engine design. 2nd ed. AIAA education ser. Reston, VA. 